\title{
Aortic flow after valve sparing root replacement with or without neosinuses reconstruction
}

\author{
Mario Gaudino, MD, ${ }^{a}$ Filippo Piatti, PhD, ${ }^{b}$ Christopher Lau, MD, ${ }^{a}$ Francesco Sturla, PhD, ${ }^{c}$ \\ Jonathan W. Weinsaft, MD, ${ }^{\mathrm{d}}$ Luca Weltert, MD, ${ }^{\mathrm{e}}$ Emiliano Votta, PhD ${ }^{\mathrm{b}}$ Nicola Galea, MD, PhD, ${ }^{\mathrm{f}, \mathrm{g}}$ \\ Ilaria Chirichilli, MD, ${ }^{e}$ Antonino Di Franco, MD, ${ }^{a}$ Marco Francone, MD, PhD, ${ }^{g}$ Carlo Catalano, MD, ${ }^{g}$ \\ Alberto Redaelli, PhD, ${ }^{\mathrm{b}}$ Leonard N. Girardi, MD, ${ }^{\mathrm{a}}$ and Ruggero De Paulis, $\mathrm{MD}^{\mathrm{e}}$
}

\section{ABSTRACT}

Objectives: This study applied advanced 4-dimensional flow magnetic resonance imaging processing to assess differences in aortic flow dynamics after valve sparing root replacement, with and without reconstruction of the Valsalva sinuses.

Methods: We enrolled patients after valve sparing root replacement with a straight tubular prosthesis $(\mathrm{n}=10)$ or with a prosthesis with Valsalva neosinuses $(\mathrm{n}=10)$; age-matched subjects without cardiovascular diseases served as controls $(\mathrm{n}=10)$. 4-Dimensional flow magnetic resonance imaging acquisitions were performed on a 3.0T magnetic resonance imaging unit. In-house processing was used to segment the aortic lumen and extract the volumetric 4-dimensional flow velocity field. Velocity flow streamlines were computed to compare the amount of rotational flow and wall shear stress. Occurrence of abnormal wall shear stress (WSS) was estimated within the descending aorta of each surgical group.

Results: Physiologic-like sinus vortices were visible in the aortic root when using the prosthesis with neosinuses, whereas straight tubular graft revealed localized intrados malrotations $(P=.003$ for organized vortical structures vs neosinuses graft and $P<.001$ vs control). In the ascending aorta, recreation of the sinuses resulted in significantly lower velocity and WSS than in the straight tubular graft $(P<.001)$ and controls $(P<.001)$, these alterations were attenuated in the mid-descending aorta. Incidence of abnormal WSS was markedly higher in the straight tube grafts than neosinus of Valsalva grafts.

Conclusions: Re-creation of the sinuses of Valsalva during valve-sparing root replacement is associated with more physiologic flow and significantly lower WSS in the aortic root. Lower WSSs in the distal thoracic aorta is a novel finding with potential implications on distal aortic remodeling. (J Thorac Cardiovasc Surg 2019; $157: 455-65)$

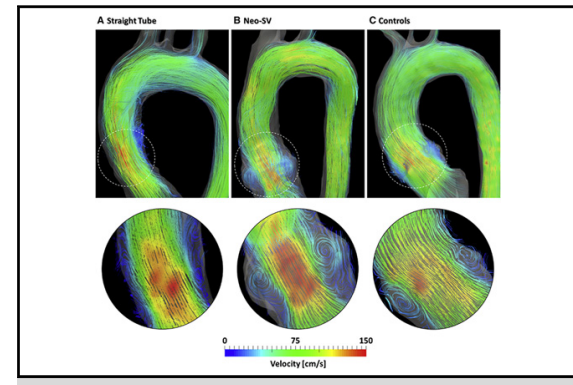

Visualization of 3D streamlines at peak systole.

\section{Central Message}

Re-creation of the SV during VSRR is associated with lower WSSs in the aortic root. Lower WSSs in the distal thoracic aorta is a novel finding with potential implications on distal aortic remodeling.

Perspective

This study is the first to systematically and quantitatively compare straight tube graft versus neo-SV graft versus control group. Intuitively, decreased shear stress and more consistent laminar flow seen with the neo-SV configuration might positively influence late aneurysm formation, especially in patients with connective tissue disorder who may be more sensitive to increased stress.

See Editorial Commentary page 466
Re-creation of the sinuses of Valsalva (SV) in valve-sparing reimplantation procedures has been a major focus of aortic valve-sparing surgery. Conceptual advantages of this approach include restoration of normal aortic flow

\footnotetext{
From the ${ }^{\mathrm{a}}$ Department of Cardiothoracic Surgery and ${ }^{\mathrm{d}}$ Department of Medicine (Cardiology), Weill Cornell Medicine, New York, NY; ${ }^{\mathrm{b}}$ Department of Electronics, Information, and Bioengineering, Politecnico di Milano, Milan, Italy; ${ }^{\mathrm{c}} 3 \mathrm{D}$ and Computer Simulation Laboratory, IRCCS Policlinico San Donato, San Donato Milanese, Italy; ${ }^{e}$ Department of Cardiac Surgery, European Hospital, Rome, Italy; and ${ }^{\mathrm{f}}$ Department of Experimental Medicine and ${ }^{\mathrm{g}}$ Department of Radiological, Oncological, and Pathological Sciences, Sapienza University of Rome, Rome, Italy.

IRCCS Policlinico San Donato is a clinical research hospital partially funded by the Italian Ministry of Health.
}

physiology via re-creation of native sinus type anatomy. However, straight tube grafts are widely utilized in clinical aortic valve-sparing surgery, and lack of high rates of valve failure or associated drawback with use of this approach

Drs Gaudino, Piatti, Sturla, Redaelli Girardi, and De Paulis contributed equally to this work.

Received for publication April 7, 2018; revisions received June 13, 2018; accepted for publication June 24, 2018; available ahead of print Aug 20, 2018.

Address for reprints: Mario Gaudino, MD, Department of Cardiothoracic Surgery, Weill Cornell Medicine, 525 E 68th St, New York, NY 10065 (E-mail mfg9004@med.cornell.edu).

0022-5223/ $\$ 36.00$

Copyright (c) 2018 by The American Association for Thoracic Surgery

https://doi.org/10.1016/j.jtcvs.2018.06.094 


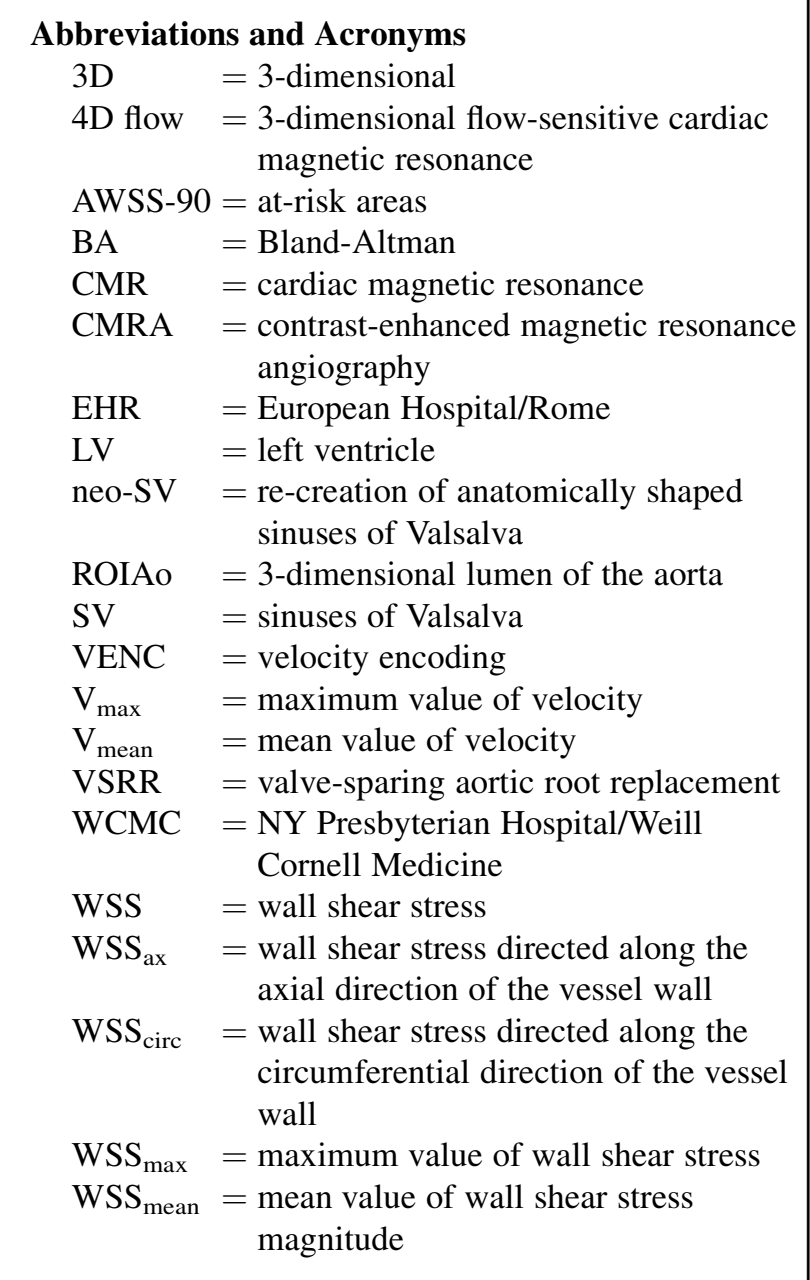

have been cited as evidence that efforts to re-create neosinuses is not warranted. $^{1}$ Given the technical complexity and challenge entailed in sinus reconstruction, broad application requires further insight into the incremental physiologic value of this approach.

Cardiac magnetic resonance (CMR) imaging enables high-resolution assessment of aortic flow and geometry, thus enabling reliable study of the influence of sinus reconstruction on aortic physiology. CMR allows for in vivo imaging, a major advantage over prior ex vivo models that preliminarily suggested advantages of neosinuses graft over straight tubes in terms of aortic flow dynamics and biomechanical outcomes. ${ }^{2-5}$ More recently, 3-dimensional flow-sensitive CMR - namely, 4-dimensional flow (4D flow) - has been exploited to assess altered aortic flow in native and postsurgical aortas. Novel 4D flow insights revealed clear evidence of organized flow vortical structures in patients with neosinus grafts, ${ }^{6}$ and enabled quantitative assessment of differential flow velocity in the ascending aorta following valve-sparing aortic root replacement (VSRR). ${ }^{7}$ Further elaborations of
4D flow data showed distinct patterns of postsurgical alterations in thoracic aortic wall shear stress (WSS). ${ }^{8}$ However, few studies to date have directly compared different VSRR prostheses and normal controls. Also, little is known about how the shape of the aortic graft can influence the downstream flow at the ascending and descending aorta after VSRR. In a preliminary study, we provided initial quantitative evaluation of the aortic root flow after VSRR with and without neosinus recreation. ${ }^{9}$

This study employed CMR 4D flow and advanced computational methods to study postsurgical patients who underwent aortic valve-sparing reimplantation with and without neosinus reconstruction. Goals were 2-fold: to quantify in vivo differences in flow parameters between aortic sinus reconstruction techniques against matched controls and to investigate differential effects of VSRR on the downstream flow in the proximal descending aorta.

\section{METHODS \\ Study Population}

Patients who underwent VSRR for correction of aortic aneurysm/ insufficiency were recruited from 2 participatory sites: New York Presbyterian Hospital/Weill Cornell Medicine (WCMC) and European Hospital/Rome (EHR) ( $n=10$ per site). VSRR was performed with or without SV re-creation at respective participatory sites, but was otherwise similar with respect to surgical methods (detailed below). At each site, patients were deemed eligible for enrollment if VSRR attained adequate surgical results (no aortic regurgitation or stenosis as verified by medical record review). Patients with genetically mediated aortopathies (eg, Marfan syndrome or bicuspid valve) were excluded. Demographic indices were acquired via medical record review blinded to CMR results.

To test magnitude of deviation of respective surgical methods from intrinsic aortic physiology, healthy subjects matched for age, sex, and body mass index, without indications of cardiovascular diseases, uncontrolled hypertension, valve dysfunctions, or aortic aneurysm, were enrolled as controls $(\mathrm{n}=10)$.

The institutional review board/ethics committee at each participating center approved the study. Written informed consent was obtained from all study participants at time of enrollment.

\section{Surgical Procedures}

Surgical operation was indicated by criteria of aortic pathology and valvular disease according to the established best practice, European Society of Cardiology/European Association for Cardio-Thoracic Surgery, ${ }^{10}$ and American College of Cardiology/American Heart Association ${ }^{11}$ guidelines. All operations consisted of replacement of the root and ascending aorta. At WCMC, a straight polyethylene terephthalate tube (Macquet Corp, Fairfield, NJ) was used for reimplantation of the aortic valve substructures following classical David I technique (straight tube graft). At EHR, reimplantation was performed within a Vascutek Gelweave Valsalva graft (Terumo, Inchinnan, Scotland) with re-creation of anatomically shaped SV (neo-SV graft). For further details of the surgical techniques employed in the 2 centers we refer readers to previous studies. ${ }^{12-14}$

\section{CMR Acquisition}

CMR examinations were performed at WCMC and Policlinico Umberto I Hospital of "Sapienza" University of Rome (EHR group). All CMR studies were performed on equivalent 3.0T scanners (Discovery MR750; GE HealthCare, Milwaukee, Wis) with a 32-channel torso phased-array 
coil, applying a prespecified research protocol composed of 3 major components to comprehensively assess aortic physiology: cine-CMR (aortic valve/cardiac structure and function), contrast-enhanced magnetic resonance angiography (CMRA) (aortic anatomy), and 4D flow (aortic flow dynamics).

Cine-CMR was performed using a steady-state free precession pulse sequence acquired en face through the aortic valve, as well as in contiguous left ventricular (LV) short axis and (2-, 3-, and 4-chamber) long axis planes. To further assess root geometry, tailored cine-CMR images were acquired longitudinal and transverse to the LV outflow tract, the latter of which was used to measure bulb transverse diameters in a standardized fashion based on cusp-commissure distance (Figure $1, A$ ). ${ }^{15}$

4D Flow was acquired with prospective electrocardiogram gating during free-breathing, using a respiratory navigator, to yield the time-dependent evolution of blood flow within the aorta (Figure 1, B). 4D Flow images were acquired in para-sagittal orientation, for which the field of view was tailored to maximize spatial resolution while encompassing the aortic root through the distal descending thoracic aorta (diaphragmatic junction). In particular, the time frame with the highest contrast between the thoracic aorta and the surrounding tissues, in terms of velocity magnitude, was identified by visual inspection and considered as peak systole. This time frame was also characterized by the highest velocity-to-noise ratio. Typical parameters were: voxel sizing $=1.48 \times 1.48 \times 1.8 \mathrm{~mm}$; flip angle $=10^{\circ}$ to $14^{\circ}$; echo time $=2.02$ to $2.15 \mathrm{~ms}$; repetition time $=4.3$ to $5.27 \mathrm{~ms}$. Peak velocity encoding (VENC) limits were adjusted to avoid signal aliasing $(\sim 150 \mathrm{~cm} / \mathrm{s}) .{ }^{16}$ Of note, if compared with previous 4D flow studies, ${ }^{6-8}$ the spatial resolution was maximized to ensure adequate number of velocity points within the aortic root, because the primary purpose of our study was to elucidate the influence of surgical root reconstruction methods on aortic root flow physiology.

CMRA was acquired during dynamic infusion of gadolinium $(0.2 \mathrm{mmol} / \mathrm{kg})$ using a gradient echo pulse sequence. Magnetic resonance angiography triggering was tailored to coincide with maximal aortic enhancement using a commercial fluoro-triggering algorithm; image acquisition was in para-sagittal orientation matched to 4D flow.

\section{CMR ANALYSIS}

4D Flow images were processed exploiting an in-house MATLAB (The MathWorks Inc, Natick, Mass) software tool and ParaView (Kitware Inc, Clifton Park, NY) environment, following approaches for dataset correction (eg, eddy currents and aliasing), aortic wall segmentation, and hemodynamic variables estimation as previously described. ${ }^{17}$ In particular, the time frame with the highest velocity to noise ratio was identified as peak systole by visual inspection. At this time point, the 3-dimensional (3-D) lumen of the aorta was extracted $\left(\mathrm{ROI}_{\mathrm{Ao}}\right)$; cine-CMR images transverse to the $\mathrm{LV}$ outflow tract were used to guide $\mathrm{ROI}_{\mathrm{Ao}}$ definitions in presence of low-velocity SV regions (EHR group and controls), as well as to identify ostia of the left and right coronary arteries (Figure 1,C).

Three different analyses were performed to characterize blood flow dynamics within the 3 groups (Figure 1,D).

The first analysis was performed positioning a long-axis plane passing through the coronary ostia and perpendicular to the valvular plane (Figure 1,D). On this plane, flow streamlines were computed to cluster the amount of in-plane rotational flow into low $\left(\Phi<90^{\circ}\right)$, mild
$\left(90^{\circ}<\Phi<180^{\circ}\right)$, moderate $\left(180^{\circ}<\Phi<270^{\circ}\right)$, and marked $\left(\Phi>270^{\circ}\right)$ rotation regions..$^{9}$

The second analysis was performed on a volumetric basis considering a region of the ascending aorta $(3.5 \mathrm{~cm}$ in length) at the level of the right pulmonary artery $\left(\mathrm{P}_{1}-\mathrm{P}_{2}\right)$ (Figure 1,C and D) and of the mid-descending aorta $\left(4.0 \mathrm{~cm}\right.$ in length) after the supra-aortic branches $\left(\mathrm{P}_{3}-\mathrm{P}_{4}\right)$ (Figure $1, C$ and $D$ ). Maximum value of velocity $\left(\mathrm{V}_{\max }\right)$, mean value of velocity $\left(\mathrm{V}_{\text {mean }}\right)$, maximum value of WSS $\left(\mathrm{WSS}_{\max }\right)$, and mean value of WSS magnitude $\left(\mathrm{WSS}_{\text {mean }}\right)$ were computed. ${ }^{18}$ The directional components of WSS were also estimated as those directed along the axial direction of the vessel wall ( $\mathrm{WSS}_{\mathrm{ax}}$ ) and along the circumferential direction of the vessel wall $\left(\mathrm{WSS}_{\text {circ }}\right)$. The ratio between their magnitudes $\left(\mathrm{WSS}_{\text {circ }}: \mathrm{WSS}_{\mathrm{ax}}\right.$ ) was computed. This analysis was accomplished averaging data from 3 time points centered on the peak systolic frame.

The third analysis was performed within the ascending aorta; that is, the $\mathrm{P}_{3}$ to $\mathrm{P}_{4}$ region, to quantify the occurrence of abnormal WSS overstimulation in patients treated with the grafts. To do so, systole-averaged maps of 3D WSS were automatically generated on the $\mathrm{ROI}_{\mathrm{Ao}}$ for each dataset. ${ }^{17}$ Heatmaps of the 3D WSS distributions were obtained on 2-dimensional templates to rule out the effects of intersubject anatomic variability (Figure 1,D). Group-specific heatmaps were than created to allow intergroup comparison between patients and controls. ${ }^{17}$ At-risk areas ( $\left.A_{\text {WSS-90 }}\right)$ were identified by those regions where the WSS of patient-specific heatmaps exceeded the WSS 90th percentile of control-subject heatmaps. The occurrence of $A_{\mathrm{WSS}-90}$ within the straight tube graft and neo-SV populations were counted on the descending aortic wall region $\left(\mathrm{P}_{3}-\mathrm{P}_{4}\right)$; heatmaps of $\mathrm{A}_{\mathrm{WsS}-90}$ were stratified according to the increasing number of patients experiencing local overstimulation. The extent of such $A_{W S S-90}$ stratifications was quantified and expressed as percentage of the overall $\mathrm{P}_{3}$ to $\mathrm{P}_{4}$ extension.

\section{Interobserver Reproducibility}

To assess the reproducibility of velocity and WSS parameters, $\mathrm{V}_{\max }, \mathrm{V}_{\text {mean }}$, $\mathrm{WSS}_{\text {max }}$, and $\mathrm{WSS}_{\text {mean }}$ values were calculated by 2 blinded and independent operators in randomized datasets taken from the WCMC $(\mathrm{n}=3)$, EHR $(\mathrm{n}=3)$, and controls $(\mathrm{n}=3)$ groups. Interobserver variability was studied using Bland-Altman (BA) analyses and Pearson correlation. BA mean biases and limits of agreement (as defined as mean \pm 1.96 standard deviation), and correlation coefficient $(r)$ are provided.

\section{Statistical Analysis}

Normal distributions of continuous variables were tested using a Shapiro-Wilk normality test. Data are reported as mean \pm standard deviation when their distribution was normal or otherwise as median 

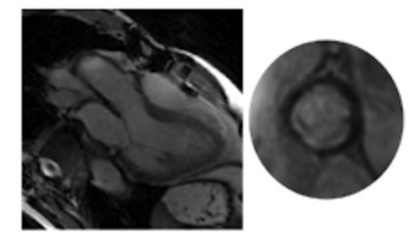

Straight Tube
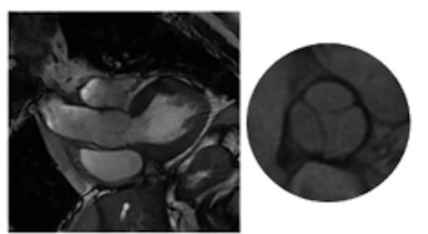

neo-Sinuses
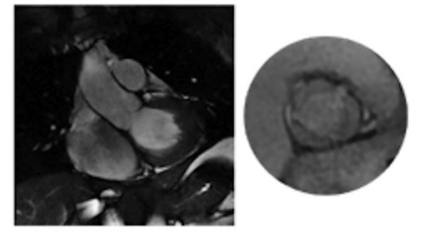

A

Controls

i)

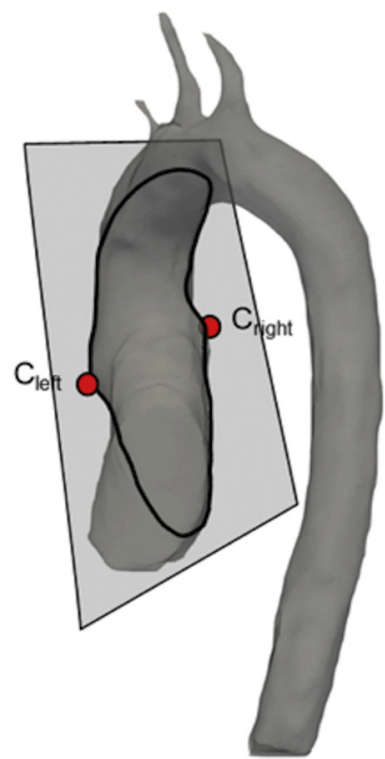

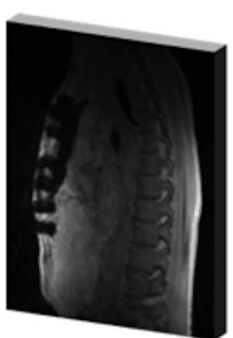
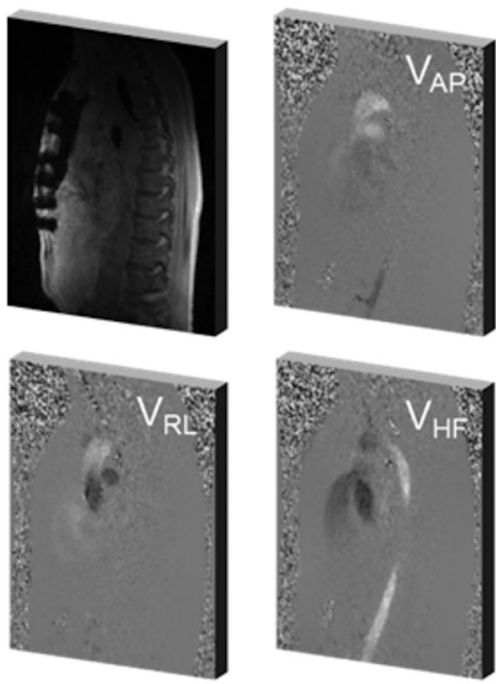

$[\mathrm{cm} / \mathrm{s}]$

+ VENC

VENC

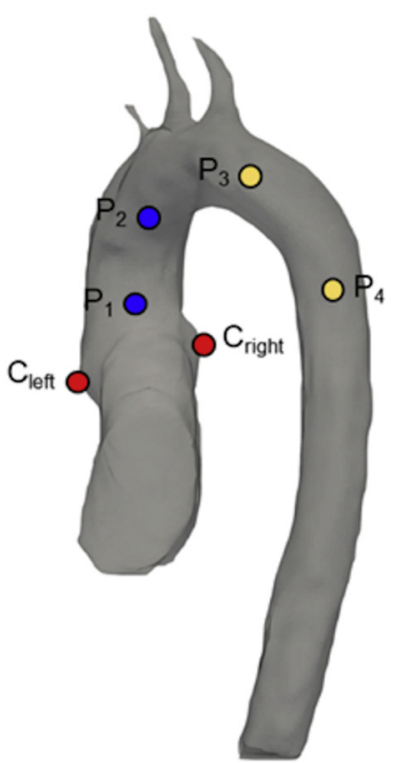

C ii)

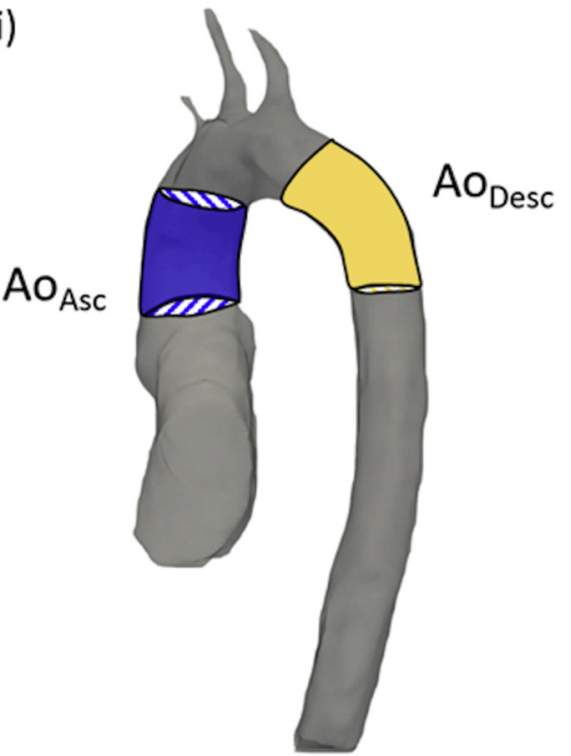

iii)
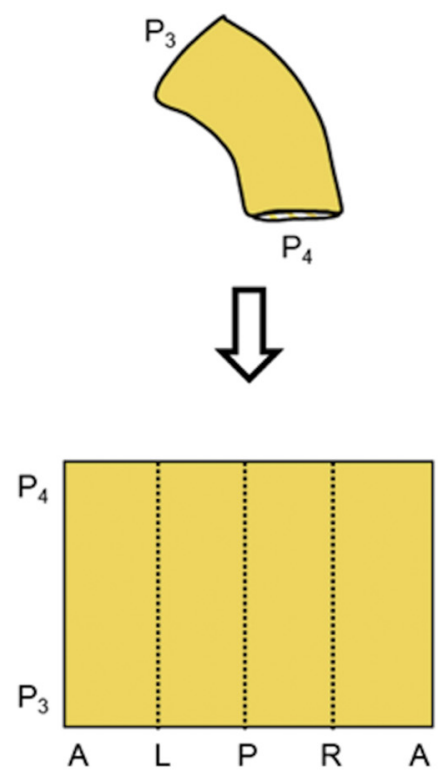

FIGURE 1. A, Representative cases of left ventricular outflow tract long-axis and short-axis cine magnetic resonance images of patients following valve-sparing root replacement with a straight tube graft or with a graft with re-creation of the neosinuses, compared with healthy controls. B, Four-dimensional flow image acquisition yielding blood flow information along directional phase encoding. C, Three-dimensional segmentation of the aorta and identification of coronaries ostia $\left(\mathrm{C}_{\text {right }}, \mathrm{C}_{\text {left }}\right)$ and anatomic landmarks on the ascending $\left(\mathrm{P}_{1}, \mathrm{P}_{2}\right)$ and descending $\left(\mathrm{P}_{3}, \mathrm{P}_{4}\right)$ aorta. $\mathrm{D}, \mathrm{Analyses}$ on 4-dimensional flow data. i) Computed rotational flows on a plane positioned within the aortic root. ii) Estimated volumetric velocity and wall shear stress distributions within the ascending $\left(\mathrm{P}_{1}-\mathrm{P}_{2}\right)$ and mid-descending $\left(\mathrm{P}_{3}-\mathrm{P}_{4}\right)$ aorta. iii) Computed group-specific wall shear stress heatmaps on the $\mathrm{P}_{3}$ to $\mathrm{P}_{4}$ region. $V$, Velocity; $A$, anterior; $P$, posterior; $R$, right; $L$, left; $H$, head; $F$, foot; $V E N C$, velocity encoding.

(interquartile range). Comparisons between straight tube graft and neo-SV graft patients were performed using unpaired $t$ test, in the case of normal distributions, or nonparametric Mann-Whitney test otherwise. Comparisons between the 3 groups were performed using analysis of variance with Tukey post hoc test for multiple comparisons, in 


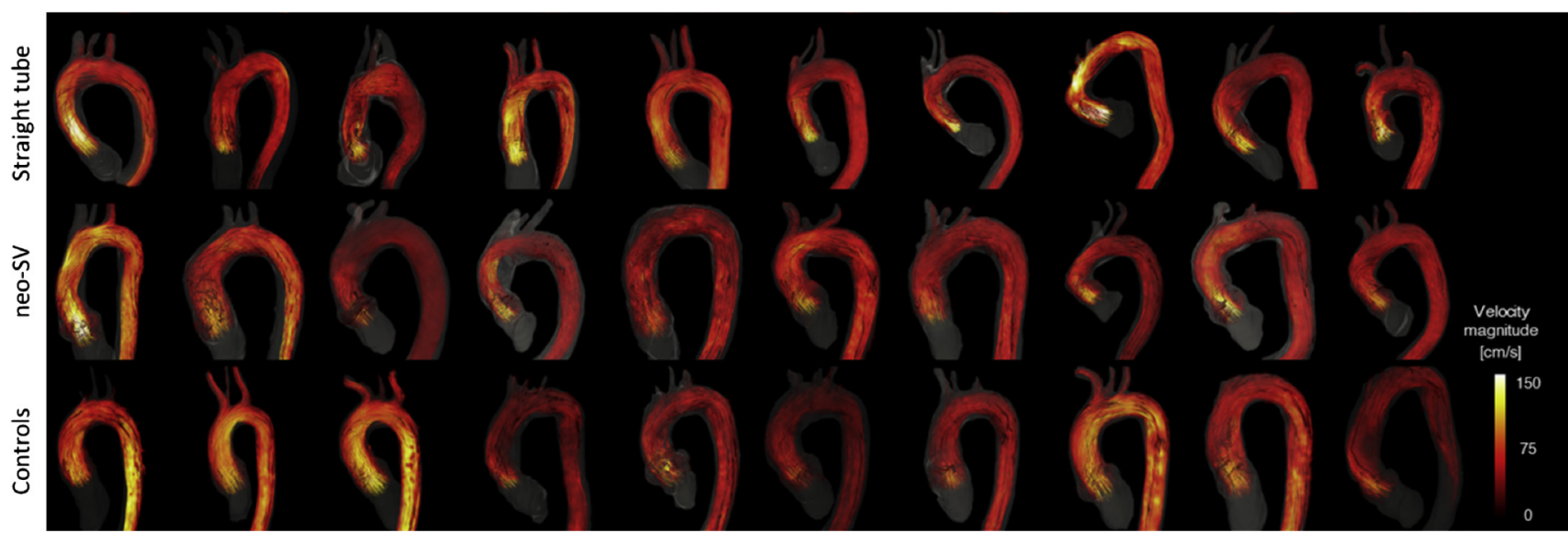

FIGURE 2. Visualization of 3-dimensional pathlines computed during the systolic phase of the cardiac cycle for patients following valve-sparing root replacement with a straight tube graft (upper panels) or with a graft with re-creation of neosinuses (neo-SV) (middle panels), compared with healthy controls (lower panels).

case of normal distributions, or nonparametric KruskalWallis test with Dunn post hoc test for multiple comparisons.

Interobserver variability was analyzed through BA plots, reporting mean biases and limits of agreement (defined as mean \pm 1.96 standard deviation). Statistical analyses were performed using GraphPad Prism 7 (GraphPad Software, Inc, La Jolla, Calif).

\section{RESULTS}

\section{Overall Aortic 3D Flow Patterns After VSRR Surgery}

All CMR acquisitions were successfully accomplished for all the enrolled patients. Interval from surgery to CMR was $2.71 \pm 3.80$ years, specifically $2.13 \pm 1.04$ years in the straight tube cohort and $3.11 \pm 4.9$ years in the neo-SV graft group.

The 3D time-dependent course of blood during the systolic phase of the cardiac cycle was analyzed by means of flow pathlines (Figure 2). Globally, no discernable flow alterations or anatomic differences among the 3 groups were detected within the thoracic aorta (eg, stenosis or aneurismal dilation), and no deviated systolic jets or concomitant abnormal helical flows were observed.

\section{Differential Rotational Flow Within the Aortic Bulb}

Differential flows were observed when considering the aortic bulb (Figure 3). In particular, the straight tube graft population was characterized by an almost rectilinear systolic flow, although evidence of occasional small and unorganized rotational flows occurring near the inner curvature of the ascending aortic wall were observed. By contrast, organized rotational flows were consistently observed in the neo-SV graft population around the aortic valve within the regions corresponding to the $\mathrm{SV}$; these flow patterns were similar to those developing in the anatomic SV of controls. Of note, rotations within the SV were persistent throughout the entire systolic opening of the aortic valve.

The percentage distribution of rotational flows $(\Phi)$ clustered within the aortic bulb confirmed the observed trend (Figure 4). In particular, the straight tube graft population showed a statistically significantly higher distribution of almost rectilinear flow patterns $\left(\Phi<90^{\circ}\right)$ with respect to the neo-SV group $(P=.0035)$ and controls $(P<.0001)$. On the other hand, the amount of flow streamlines corresponding to full rotations $\left(\Phi>270^{\circ}\right)$; that is, organized vortical structures within the $\mathrm{SV}$, were significantly lower in the straight tube graft population ( $P=.0032$ vs neo-SV; $P<.0001$ vs controls).

\section{Alterations in Blood Flow and WSS}

We observed differences for velocity and WSS volumetric distributions, both considering the ascending $\left(\mathrm{P}_{1}-\mathrm{P}_{2}\right)$ and descending aorta $\left(\mathrm{P}_{3}-\mathrm{P}_{4}\right)($ Table 1$)$. Despite no statistically significant differences in terms of cardiac output $(P=.32)$, aortic diameters $(P=.14)$, and heart rate $(P=.39)$ among the 3 groups (Table 2), the straight tube graft group showed a higher $\mathrm{V}_{\text {mean }}$ than did the neo-SV graft group $(P<.001)$ and controls $(P<.001)$ at the level of ascending aorta. These differences were even more emphasized for $\mathrm{V}_{\max }$, with both patient groups characterized by higher values than controls $(P<.001$ straight tube vs controls; $P=.002$, neo-SV vs controls), and neo-SV lower than straight tube group $(P<.001)$.

By contrast, when considering the mid-descending aorta $\left(\mathrm{P}_{3}-\mathrm{P}_{4}\right)$, these alterations were attenuated; despite $\mathrm{V}_{\max }$ being comparable between groups $(P=.16)$, higher $\mathrm{V}_{\text {mean }}$ values were reported in the straight tube grafts $(P=.002)$.

Consistent with velocity alterations in the $\mathrm{P}_{1}$ to $\mathrm{P}_{2}$ region, the neo-SV graft group and controls had similar WSS 


\section{A Straight Tube}
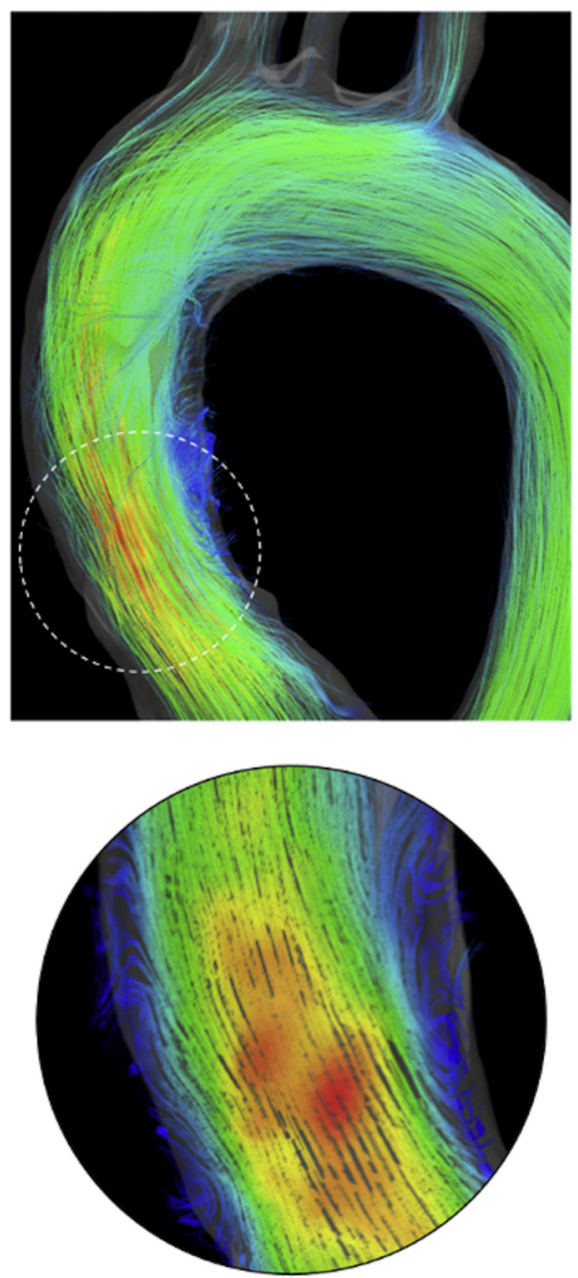

B Neo-SV
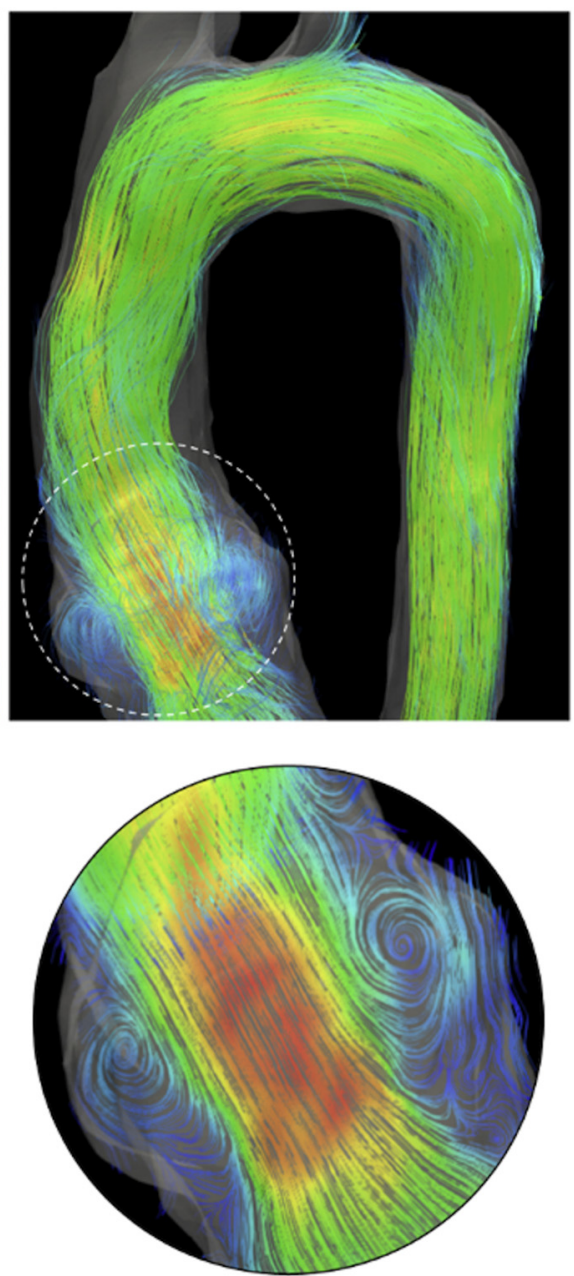

75

\section{Controls}
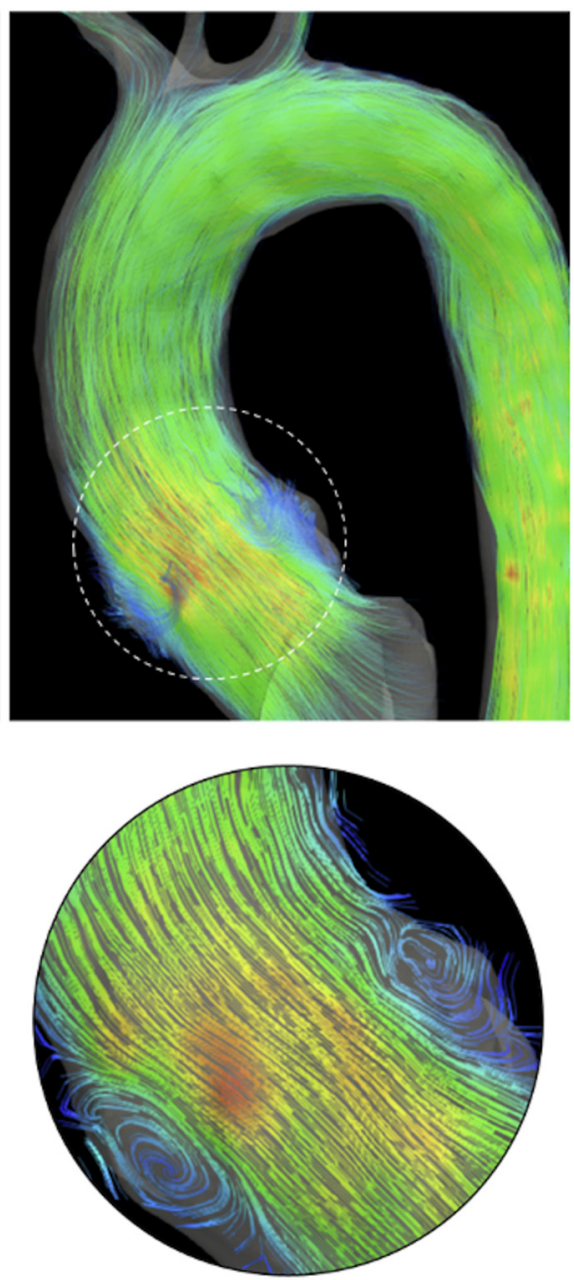

150

\section{Velocity $[\mathrm{cm} / \mathrm{s}]$}

FIGURE 3. Visualization of 3-dimensional streamlines at the timeframe identified as peak systole in a straight tubular graft. A, Valsalva neosinuses (neo-SV) graft. B, Control. C, Presence of comparable rotational flow patterns was noticeable, close to the coronary ostia, in the neo-SV graft and in the control.

stimuli acting on the aortic wall; the straight tube group was characterized both by higher and significantly different WSS $_{\max }$ distributions $(P<.001$ vs neo-SV; $P<.001$ vs controls $)$ and $\mathrm{WSS}_{\text {mean }}(P<.001$ vs neo-SV; $P<.001$ vs controls).

In the $\mathrm{P}_{3}$ to $\mathrm{P}_{4}$ region, the straight tube group maintained significantly higher WSS values, whereas the neo-SV graft group was characterized by a significantly lower $\mathrm{WSS}_{\text {mean }}$ with respect to controls $(P=.004)$.

The ratio of $\mathrm{WSS}_{\text {circ }}$ to $\mathrm{WSS}_{\mathrm{ax}}$ was altered for both patient groups in the $\mathrm{P}_{1}$ to $\mathrm{P}_{2}$ region, being higher than controls $(P=.006$ vs straight tube; $P<.001$ vs neo-SV). This alteration was maintained only for the neo-SV group in the $\mathrm{P}_{3}$ to $\mathrm{P}_{4}$ region, characterized by a WSS $\mathrm{Wirc}_{\text {co }}$ to $\mathrm{WS}_{\mathrm{ax}}$ ratio higher than the straight tube group $(P=.005)$ and controls $(P=.005)$.

\section{Incidence of WSS Alterations Acting on the Descending Aortic Wall}

Patient-specific WSS heatmaps were computed for all the analyzed datasets, yielding group-specific WSS distributions acting on the descending aortic wall $\left(\mathrm{P}_{3}-\mathrm{P}_{4}\right)$, as shown for controls in Figure 5, A. Both groups of patients were compared with the WSS representative distribution obtained for controls, pointing out a larger occurrence of WSS overstimulation of the aortic wall for the straight 

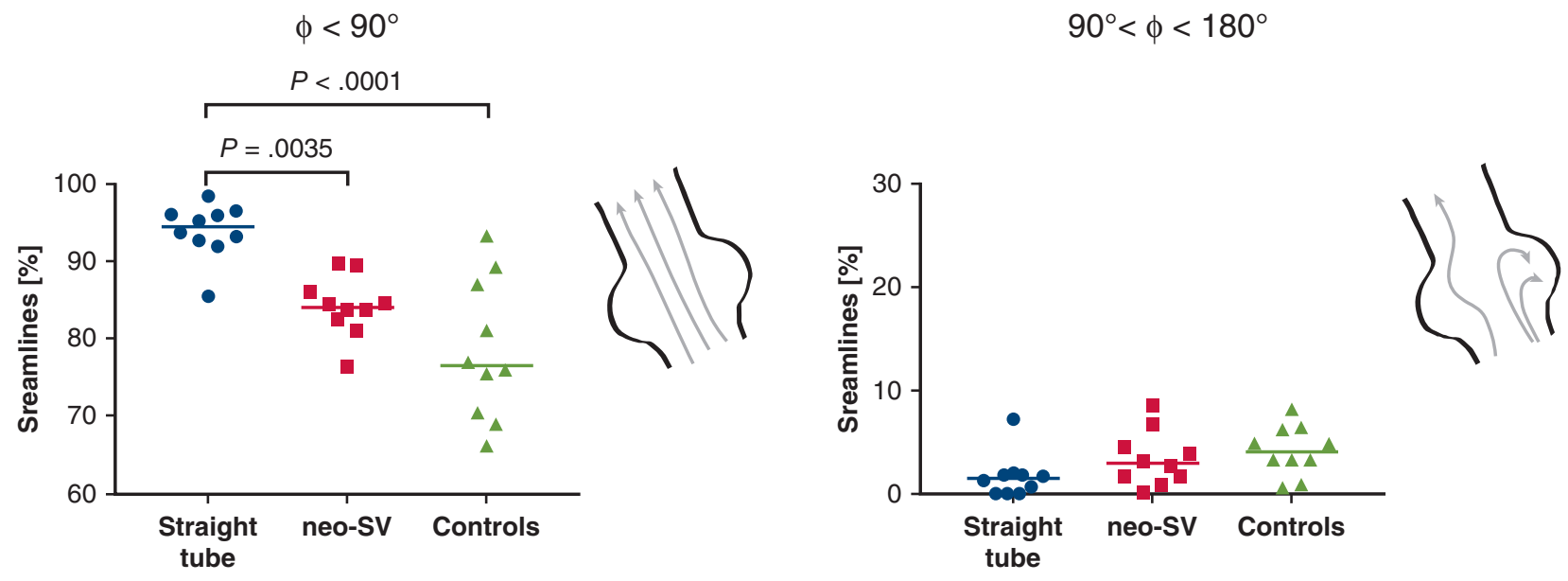

$180^{\circ}<\phi<270^{\circ}$

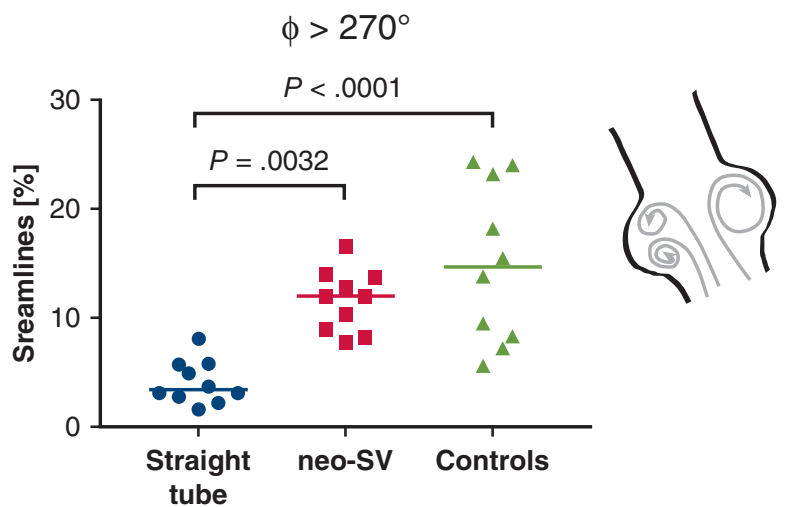

FIGURE 4. Clustering of the flow streamlines, computed on the plane passing through the coronaries ostia and perpendicular to the valvular plane, into low $\left(\Phi<90^{\circ}\right)$, mild $\left(90^{\circ}<\Phi<180^{\circ}\right)$, moderate $\left(180^{\circ}<\Phi<270^{\circ}\right)$, and marked $\left(\Phi>270^{\circ}\right)$ rotational flow regions. Data are represented as dot plots with a horizontal line highlighting the median values: straight tube $(\mathrm{n}=10)$ (blue circles); re-creation of anatomically shaped sinuses of Valsalva (neo-SV) $(\mathrm{n}=10)$ (red squares); and controls $(\mathrm{n}=10)$ (green triangles). Statistically significant $P$ values of Dunn post hoc test are reported for multiple group comparisons.

tube group with respect to the neo-SV graft population (Figure 5, B). Despite a negligible WSS increase along the anterior portion of the aortic wall in both patient populations, a marked increase in WSS was reported in the left wall region, involving up to $80 \%$ and $30 \%$ of patients with straight tube and neo-SV grafts, respectively.

\section{Interobserver Variability in Data Processing}

Results of BA analyses (ie, interobserver biases and limits of agreement) and Pearson correlation coefficient for aortic velocity and WSS variables are provided in Table 3, and indicate a good level of reproducibility.

\section{DISCUSSION}

The merits of preserving native valvular tissue when performing valve surgery or aneurysm repair has been well established because native valve repairs have the potential to offer a lifelong functioning valve that is at minimal risk for structural deterioration and does not require anticoagulation therapy. ${ }^{19}$ Development of the reimplantation technique for VSRR has allowed for dissemination of a reliable and reproducible method of replacing the aortic sinuses while preserving the native aortic valve. ${ }^{14}$ This technique was developed using straight polyethylene terephthalate tube grafts, which were the only grafts commercially available, but the introduction of grafts recreating the SV allowed surgeons to offer repairs that mimic the shape of the native aortic root and sinuses. ${ }^{20}$ Although the neo-SV grafts offered a more physiologicappearing result, in the published series the short- to midterm clinical and echocardiographic outcomes did not differ significantly between the 2 groups. ${ }^{13}$ Because VSRR is often performed in younger patients, the quest to develop techniques that lead to the best valve durability and lowest risk of future aortic events is of upmost importance.

Advances in 4D flow magnetic resonance imaging technology and computational methods have allowed for in vivo assessment of the effects of aortic root replacement on blood flow within a replaced aorta as well as the native 
TABLE 1. Results of bulk flow aortic analysis

\begin{tabular}{|c|c|c|c|c|}
\hline Variable & $\begin{array}{l}\text { Straight tube } \\
\quad(\mathbf{n}=\mathbf{1 0})\end{array}$ & $\begin{array}{l}\text { Neosinus of Valsalva } \\
\qquad(\mathbf{n}=\mathbf{1 0})\end{array}$ & $\begin{array}{l}\text { Controls } \\
(\mathbf{n}=10)\end{array}$ & $P$ value \\
\hline \multicolumn{5}{|l|}{ Ascending aorta $\left(\mathrm{P}_{1}-\mathrm{P}_{2}\right)$} \\
\hline $\mathrm{V}_{\max }(\mathrm{cm} / \mathrm{s})$ & $100.9(83.9-125.1)^{*}, \dagger$ & $78.8(72.0-96.2) \dagger$ & $68.5(52.5-84.7)$ & $<.001$ \\
\hline $\mathrm{V}_{\text {mean }}(\mathrm{cm} / \mathrm{s})$ & $46.1(39.9-58.3)^{*}, \dagger$ & $36.1(34.2-40.1)$ & $33.5(24.4-42.0)$ & $<.001$ \\
\hline $\mathrm{WSS}_{\max }(\mathrm{Pa})$ & $0.59(0.75-0.51)^{*}, \dagger$ & $0.45(0.38-0.56)$ & $0.41(0.30-0.55)$ & $<.001$ \\
\hline $\mathrm{WSS}_{\text {mean }}(\mathrm{Pa})$ & $0.24(0.19-0.29)^{*}, \dagger$ & $0.16(0.14-0.19)$ & $0.18(0.13-0.26)$ & $<.001$ \\
\hline $\mathrm{WSS}_{\text {circ }}(\mathrm{Pa})$ & $0.08(0.06-0.1)^{*}, \dagger$ & $0.06(0.05-0.08) \dagger$ & $0.05(0.04-0.07)$ & $<.001$ \\
\hline $\mathrm{WSS}_{\mathrm{ax}}(\mathrm{Pa})$ & $0.22(0.17-0.26)^{*}, \dagger$ & $0.14(0.11-0.17) \dagger$ & $0.16(0.11-0.24)$ & $<.001$ \\
\hline $\mathrm{WSS}_{\text {circ }}: \mathrm{WSS}_{\mathrm{ax}}(\%)$ & $38(30-47) \dagger$ & $41(32-59) \dagger$ & $33(26-40)$ & $<.001$ \\
\hline \multicolumn{5}{|l|}{ Descending aorta $\left(\mathrm{P}_{3}-\mathrm{P}_{4}\right)$} \\
\hline $\mathrm{V}_{\max }(\mathrm{cm} / \mathrm{s})$ & $71.1(58.8-84.0)$ & $64.2(56.1-86.7)$ & $66.7(49.1-88.3)$ & .16 \\
\hline $\mathrm{V}_{\text {mean }}(\mathrm{cm} / \mathrm{s})$ & $42.7(36.3-50.0)^{*}$ & $35.6(32.1-47.5)$ & $41.5(26.7-54.6)$ & .002 \\
\hline $\mathrm{WSS}_{\max }(\mathrm{Pa})$ & $0.62(0.52-0.73)^{*}, \dagger$ & $0.42(0.32-0.56)$ & $0.46(0.35-0.68)$ & $<.001$ \\
\hline $\mathrm{WSS}_{\text {mean }}(\mathrm{Pa})$ & $0.36(0.28-0.44)^{*}, \dagger$ & $0.21(0.16-0.32) \dagger$ & $0.32(0.20-0.39)$ & $<.001$ \\
\hline $\mathrm{WSS}_{\text {circ }}(\mathrm{Pa})$ & $0.07(0.05-0.11)^{*}, \dagger$ & $0.05(0.04-0.07)$ & $0.06(0.04-0.09)$ & $<.001$ \\
\hline $\mathrm{WSS}_{\mathrm{ax}}(\mathrm{Pa})$ & $0.33(0.27-0.41)^{*}, \dagger$ & $0.20(0.14-0.30) \dagger$ & $0.31(0.17-0.38)$ & $<.001$ \\
\hline $\mathrm{WSS}_{\text {circ }}: \mathrm{WSS}_{\mathrm{ax}}(\%)$ & $23(16-32)^{*}$ & $27(22-34) \dagger$ & $23(18-31)$ & .002 \\
\hline
\end{tabular}

Data are expressed as median (interquartile range). $V_{\text {max }}$, Maximum value of velocity; $V_{\text {mean }}$, mean value of velocity; $W S S_{\max }$, maximum wall shear stress; WSS $S_{\text {mean }}$, mean wall shear stress; $W S S_{\text {circ }}$, wall shear stress directed along the circumferential direction of the vessel wall; $W_{S S_{a x}}$, wall shear stress directed along the axial direction of the vessel wall. $* P<.05$ versus neosinus of Valsalva based on 1-way analysis of variance post hoc multiple comparison. ${ }^{\dagger} P<.05$ versus controls based on 1-way analysis of variance post hoc multiple comparison.

distal aorta. With this technique it is possible to appreciate blood vorticity in the bulb, as postulated by Leonardo da Vinci in the 16th century. ${ }^{21}$ Indeed, the bulb shape of the native aortic root leaves a space between the leaflets of the open aortic valve and the aortic wall, and in this space, vortical blood flow is present. Fluid-structure interaction models based on finite element methodology have shown that the vortices generated in the SV prevent the leaflets from impacting with the aortic wall during systole and facilitate smooth closure of the aortic valve by directing the retrograde flow orthogonal to the surface of the leaflets. ${ }^{22}$ This was confirmed in clinical studies comparing

TABLE 2. Demographic characteristics, aortic valve function, and aorta dimensions of the populations

\begin{tabular}{|c|c|c|c|c|}
\hline Variable & $\begin{array}{l}\text { Straight tube } \\
\qquad(\mathrm{n}=\mathbf{1 0})\end{array}$ & $\begin{array}{l}\text { Neosinus of Valsalva } \\
\qquad(\mathbf{n}=\mathbf{1 0})\end{array}$ & $\begin{array}{l}\text { Control } \\
(\mathbf{n}=10)\end{array}$ & $P$ value \\
\hline Men & $9(90)$ & $10(100)$ & $10(100)$ & - \\
\hline Age $(y)$ & $55.9 \pm 15.9$ & $56.8 \pm 11.2$ & $50.1 \pm 15.6$ & .67 \\
\hline Height $(\mathrm{cm})$ & $181.4 \pm 7.6^{*}$ & $175.7 \pm 5.1$ & $173.9 \pm 6.4$ & .04 \\
\hline Weight (kg) & $85.1 \pm 17.4$ & $85.5 \pm 10.9$ & $75.3 \pm 8.8$ & .16 \\
\hline Aortic valve, TAV (\%) & $10(100)$ & $10(100)$ & $10(100)$ & 1.00 \\
\hline AI: I, II, III, IV $\dagger$ & $8,2,0,0$ & $7,2,0,0$ & $0,0,0,0$ & - \\
\hline AS: I, II, III, IV $\dagger$ & $0,0,0,0$ & $0,0,0,0$ & $0,0,0,0$ & - \\
\hline Heart rate (bpm) & $62.0 \pm 9.4$ & $62.8 \pm 8.1$ & $57.5 \pm 10.0$ & .39 \\
\hline $\mathrm{CO}(\mathrm{L} / \mathrm{min})$ & $5.7 \pm 1.4$ & $4.8 \pm 0.8$ & $5.5 \pm 1.4$ & .32 \\
\hline $\mathrm{D}_{\text {Bulb }}(\mathrm{cm})$ & $27.8 \pm 0.8^{*}, \ddagger$ & $35.4 \pm 07$ & $33.7 \pm 3.5$ & $<.001$ \\
\hline $\mathrm{D}_{\mathrm{Asc}}(\mathrm{cm})$ & $29.6 \pm 3.9$ & $30.9 \pm 1.7$ & $31.5 \pm 4.3$ & .14 \\
\hline $\mathrm{D}_{\text {Arch }}(\mathrm{cm})$ & $27.8 \pm 5.1$ & $28.0 \pm 5.1$ & $28.4 \pm 4.7$ & .96 \\
\hline $\mathrm{D}_{\text {Desc }}(\mathrm{cm})$ & $24.8 \pm 2.2$ & $26.3 \pm 4.3$ & $23.0 \pm 3.0$ & .10 \\
\hline $\mathrm{D}_{\text {Tube }}(\mathrm{cm})$ & $29.6 \pm 0.8$ & $30 \pm 0.9$ & na & .63 \\
\hline Time from operation (mo) & $38(25-40)$ & $28(20-77)$ & na & .83 \\
\hline
\end{tabular}

Data for continuous variables with normal distribution expressed as mean \pm standard deviation, time from operation is expressed as median (interquartile range), data for gender and presence of TAV are expressed as n (\%), and classifications of AI and AS are expressed as n. TAV, Tricuspid aortic valve; $A I$, aortic insufficiency; $A S$, aortic stenosis; $C O$, cardiac output; $D$, diameter; $A s c$, ascending aorta; Desc, descending aorta; $n a$, not available. ${ }^{*} P<.05$ versus controls based on 1 -way analysis of variance post hoc multiple comparison. $\nmid \mathrm{AI}$ and AS were classified as I, trivial (none/trace); II, mild; III, moderate; or IV, severe. $\ddagger P<.05$ versus neosinus of Valsalva based on 1-way analysis of variance post hoc multiple comparison. 


\section{Controls Heatmap}

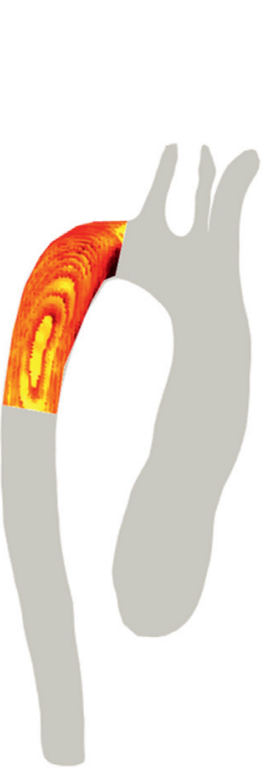

A

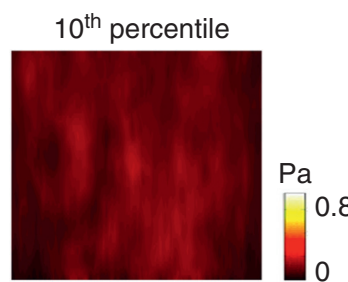

$50^{\text {th }}$ percentile

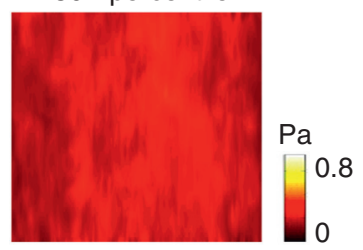

$90^{\text {th }}$ percentile

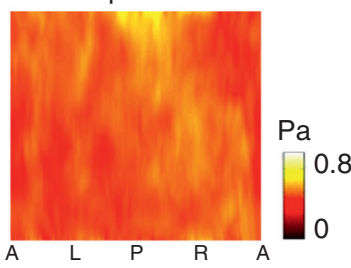

\section{WSS risk stratification}
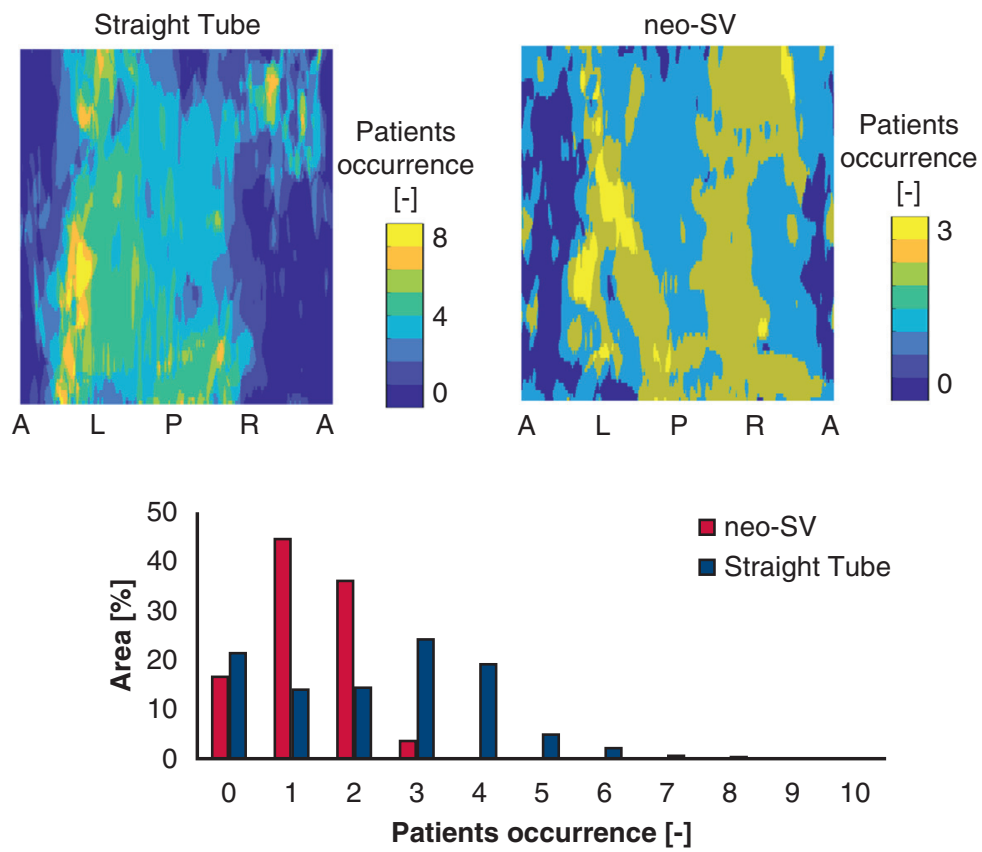

B

FIGURE 5. A, Representative visualization of the 3-dimensional wall shear stress (WSS) distribution computed over the 3-dimensional lumen of the aorta and of the 2-dimensional heatmap extracted for the control population, herein reported as 10th, 50th, and 90th percentiles of the distribution. The same heatmaps were computed for patients treated with grafts to define at-risk areas as those regions where the WSS of a patient-specific heatmap exceeded the WSS 90th percentile of a control heatmap. B, Heatmaps of at-risk areas were stratified according to the increasing number of patients locally resulting overstimulated (upper panel), and the extent of at-risk stratifications was quantified as percentage of the overall $\mathrm{P}_{3}$ to $\mathrm{P}_{4}$ extension (lower panel). neo-SV, Re-creation of anatomically shaped sinuses of Valsalva; $A$, anterior; $L$, left; $P$, posterior; $R$, right.

patients with neo-SV to normal patients, both of whom had similar vortices in the sinuses. ${ }^{6}$ Studies on straight grafts have been less consistent in demonstrating the presence of vortices in the SV, although this may be due to the use of less rigorous imaging algorithms. ${ }^{23}$

This study is the first to systematically and rigorously compare 3 groups (patients with a straight tube graft, a neo-SV graft, and controls) simultaneously in a single study and provide quantitative comparisons. Both the straight tube and neo-SV techniques led to a well-functioning valve and trace or no aortic insufficiency in follow-up to date.
Clinical outcomes were similarly excellent with no major complications.

Analysis of flow within the aortic sinuses confirmed that the flow in the neo-SV group more closely mimicked the flow in control patients and displayed a statistically significantly higher distribution of rotational flow patterns than the rectilinear flow patterns seen in the straight tube group. These findings of increased vortical streamlines are seen in systole. Although there exists a solid understanding of the advantages of having SV for diastolic blood flow, more recently, the SV seem to play a significant role in

TABLE 3. Bland-Altman biases (limits of agreement) and Pearson correlation coefficient $(r)$ for the interobserver variability analysis of velocity and regional aortic wall shear stress variables

\begin{tabular}{|c|c|c|c|c|c|c|}
\hline \multirow[b]{2}{*}{ Velocity } & \multicolumn{2}{|c|}{$\begin{array}{l}\text { Straight tube } \\
\quad(\mathbf{n}=\mathbf{3})\end{array}$} & \multicolumn{2}{|c|}{$\begin{array}{l}\text { Neosinus of Valsalva } \\
\qquad(\mathbf{n}=\mathbf{3})\end{array}$} & \multicolumn{2}{|l|}{$\begin{array}{c}\text { Controls } \\
(\mathbf{n}=\mathbf{3})\end{array}$} \\
\hline & Bland-Altman & $r$ & Bland-Altman & $r$ & Bland-Altman & $r$ \\
\hline $\mathrm{V}_{\max }(\mathrm{cm} / \mathrm{s})$ & $2.12(-2.99$ to 7.24$)$ & 0.99 & $0.72(-10.26$ to 11.71$)$ & 0.92 & $0.29(-3.44$ to 4.02$)$ & 0.97 \\
\hline $\mathrm{V}_{\text {mean }}(\mathrm{cm} / \mathrm{s})$ & $-1.67(-7.64$ to 4.31$)$ & 0.95 & $-0.39(-5.06$ to 4.27$)$ & 0.92 & -0.15 ( -3.97 to 3.68$)$ & 0.91 \\
\hline $\mathrm{WSS}_{\max }(\mathrm{Pa})$ & $-0.03(-0.19$ to 0.12$)$ & 0.73 & $-0.00(-0.11$ to 0.11$)$ & 0.72 & $-0.01(-0.12$ to 0.09$)$ & 0.75 \\
\hline $\mathrm{WSS}_{\text {mean }}(\mathrm{Pa})$ & $-0.06(-0.17$ to 0.06$)$ & 0.84 & $-0.01(-0.08$ to 0.06$)$ & 0.85 & $-0.01(-0.07$ to 0.06$)$ & 0.89 \\
\hline
\end{tabular}

$V_{\text {max }}$, Maximum value of velocity; $V_{\text {mean }}$, mean value of velocity; $W S S_{\text {max }}$, maximum wall shear stress; $W S S_{\text {mean }}$, mean wall shear stress. 
systole, allowing for easier opening of the valve, especially under exercise conditions. ${ }^{4,5}$ These findings gain new momentum in light of the present findings, which show that blood flow in the neo-SV group is more similar to controls than to patients in the straight tube group in terms of velocity and trajectories during systolic flow.

Several recent studies have shown that straight tube grafts also seem to respond to exercise by increasing the functional effective orifice during exercise. ${ }^{24,25}$ Differences in acquisition methodology (echocardiogram vs magnetic resonance imaging) or possible oversizing of the straight tube (thus somehow creating more space and mimicking the presence of neosinuses) may explain these prior findings. Our current 4D flow results show a less favorable flow pattern, which is unlikely to result in substantial flow increase using the straight tube graft.

4D Flow has demonstrated that separate vortices have been documented for each sinus, thus confuting a traditional objection raised against the Valsalva graft, the fact that a single dysmorphic bulb-shaped chamber is created due to the lack of preformed triple sinuses. ${ }^{19}$ The small areas of plication formed from the suturing and reimplanting of the valve appears to modify the initial bulbar shape, resulting in a final morphology consisting of 3 separate sinus shapes, as described previously by De Paulis and colleagues. ${ }^{13}$

Aside from differences in blood flow patterns, variations in the velocity of blood flow were apparent, likely due to flow acceleration from lack of the physiologic reservoir function of the native ascending aorta. Without a compliant ascending aorta to absorb the kinetic energy of systolic ejection, flow velocity in the ascending aorta was higher in both surgical groups compared with controls. Of note, velocities were significantly higher in the straight tube group compared with the neo-SV group. The presence of SV may serve some reservoir function but more likely helps to produce more organized and laminar flow. In the mid-descending aorta, where much of the energy has already dispersed, the findings were much subtler.

Estimations of WSS displayed a similar trend to flow velocity with a high WSS in the straight tube group compared with the neo-SV or controls groups. When the components of WSS were separated, the ratio between $\mathrm{WSS}_{\text {circ }}$ and $\mathrm{WSS}_{\mathrm{ax}}$ was higher in the neo-SV group than in the straight tube group, despite an overall lower $\mathrm{WSS}_{\text {mean }}$ and $\mathrm{WSS}_{\max }$. Perhaps this indicates that the higher flow velocities in the straight tube group are associated with a higher axial component of WSS rather than circumferential component, whereas in the neo-SV group the slower flow velocity allows for a larger circumferential component of WSS.

The long-term clinical implications of the described differences in flow cannot be established by our study. Although many groups have published excellent clinical results with both techniques, ${ }^{13,14,26}$ traditional clinical end points may not be fully adequate for this generally younger patient cohort that receives valve-sparing operations. The long-term effect of changes in flow on the distal aorta, left ventricular afterload, coronary perfusion, the valve leaflets themselves, and other components of the circulatory system are unknown at present. ${ }^{27,28}$ Intuitively, decreased shear stress and more consistent laminar flow seen with the neo-SV configuration might positively influence late aneurysm formation, especially in patients with connective tissue disorder such as Marfan, Ehlers-Danlos, and Loeys-Dietz syndromes, who may be more sensitive to increased stress.

\section{Limitations}

The study has some limitations that should be taken into account.

The first is the limited size $(n=10)$ of each group. Nonetheless, statistically significant differences between groups were found. A lack of standardized protocols and criteria to manage data extraction and representation prevent direct comparison between different 4D flow studies as well as the adoption of standardized cutoffs (eg, WSS). Second, 4D flow analysis was performed only after VSRR on selected patients. Future studies will have to focus on the correlation between preoperative aortic fluid dynamics and postoperative outcomes.

Third, a single VENC 4D flow acquisition only allowed capture of aortic flow during systole. A multi-VENC 4D flow approach ${ }^{29}$ may be warranted to effectively assess also diastolic aortic flow to evaluate in vivo the quantification of coronary artery perfusion, which is still limited to in vitro approaches. ${ }^{30,31}$

Fourth, our 4D flow technique conventionally measures a spatiotemporal averaged velocity field over multiple cardiac cycles and is therefore unable to estimate the intensity of small-scale velocity cardiovascular fluctuations that can be correlated with turbulent flow effects. ${ }^{32}$

\section{CONCLUSIONS}

Recreating neo-SV seems to lead to a pattern of blood flow that is more similar to that seen in the native SV in terms of velocities, vorticity, and trajectories during systolic flow. Neo-SV grafts result in organized vortical flow in the sinuses, lower flow velocities, and lower WSS. The clinical influence of these findings remains at present unclear.

4D Flow imaging is a promising technique that can be used to obtain reliable in vivo findings that may help answer long-standing questions that in vitro studies alone could not answer. It will likely be a valuable tool in the future to further refine anatomy and physiology in the never-ending quest to find the perfect surgical technique.

\section{Conflict of Interest Statement}

Dr De Paulis receives royalties on the Terumo Valsalva Graft because he designed and patented the original project. 
All other authors have nothing to disclose with regard to commercial support.

\section{References}

1. David TE. Aortic valve sparing in different aortic valve and aortic root conditions. J Am Coll Cardiol. 2016;68:654-64.

2. Erasmi A, Sievers H-H, Scharfschwerdt M, Eckel T, Misfeld M. In vitro hydrodynamics, cusp-bending deformation, and root distensibility for different types of aortic valve-sparing operations: Remodeling, sinus prosthesis, and reimplantation. J Thorac Cardiovasc Surg. 2005;130:1044-9.

3. Maselli D, Weltert L, Scaffa R, Nardella S, Guerrieri Wolf L, De Paulis R. Differences in aortic cusp coaptation between the reimplantation and the remodeling techniques of aortic valve-sparing surgery: an in vitro porcine model study. J Thorac Cardiovasc Surg. 2014;147:615-8.

4. Pisani G, Scaffa R, Ieropoli O, Dell'Amico EM, Maselli D, Morbiducci U, et al. Role of the sinuses of Valsalva on the opening of the aortic valve. J Thorac Cardiovasc Surg. 2013;145:999-1003.

5. Salica A, Pisani G, Morbiducci U, Scaffa R, Massai D, Audenino A, et al. The combined role of sinuses of Valsalva and flow pulsatility improves energy loss of the aortic valve. Eur J Cardiothorac Surg. 2016:49:1222-7.

6. Oechtering TH, Hons CF, Sieren M, Hunold P, Hennemuth A, Huellebrand M, et al. Time-resolved 3-dimensional magnetic resonance phase contrast imaging (4D flow MRI) analysis of hemodynamics in valve-sparing aortic root repair with an anatomically shaped sinus prosthesis. J Thorac Cardiovasc Surg. 2016;152:418-27.e1.

7. Semaan E, Markl M, Malaisrie SC, Barker A, Allen B, McCarthy P, et al. Haemodynamic outcome at four-dimensional flow magnetic resonance imaging following valve-sparing aortic root replacement with tricuspid and bicuspid valve morphology. Eur J Cardiothorac Surg. 2014;45:818-25.

8. Bollache E, Fedak PWM, van Ooij P, Rahman O, Malaisrie SC, McCarthy PM, et al. Perioperative evaluation of regional aortic wall shear stress patterns in patients undergoing aortic valve and/or proximal thoracic aortic replacement. J Thorac Cardiovasc Surg. 2018;155:2277-86.e2

9. Galea N, Piatti F, Sturla F, Weinsaft J, Lau C, Chirichill I, et al, Novel insights by 4D flow imaging on aortic flow physiology after valve-sparing replacement with or without neosinuses. Interact Cardiovasc Thorac Surg. 2018;26:957-64.

10. Erbel R, Aboyans V, Boileau C, Bossone E, Bartolomeo RD, Eggebrecht H, et al. 2014 ESC guidelines on the diagnosis and treatment of aortic diseases: document covering acute and chronic aortic diseases of the thoracic and abdominal aorta of the adult. The task force for the diagnosis and treatment of aortic diseases of the European Society of Cardiology (ESC). Eur Heart J. 2014:35:2873-926.

11. Hiratzka LF, Bakris GL, Beckman JA, Bersin RM, Carr VF, Casey DE Jr, et al. 2010 ACCF/AHA/AATS/ACR/ASA/SCA/SCAI/SIR/STS/SVM guidelines for the diagnosis and management of patients with thoracic aortic disease: a report of the American College of Cardiology Foundation/American Heart Association task force on practice guidelines, American Association for Thoracic Surgery, American College of Radiology, American Stroke Association, Society of Cardiovascular Anesthesiologists, Society for Cardiovascular Angiography and Interventions, Society of Interventional Radiology, Society of Thoracic Surgeons, and Society for Vascular Medicine. Circulation. 2010;121:e266-369.

12. De Paulis R, De Matteis GM, Nardi P, Scaffa R, Buratta MM, Chiariello L. Opening and closing characteristics of the aortic valve after valve-sparing procedures using a new aortic root conduit. Ann Thorac Surg. 2001;72:487-94.

13. De Paulis R, Chirichilli I, Scaffa R, Weltert L, Maselli D, Salica A, et al. Long-term results of the valve reimplantation technique using a graft with sinuses. J Thorac Cardiovasc Surg. 2016;151:112-9.

14. Gaudino M, Lau C, Munjal M, Avgerinos D, Girardi LN. Contemporary outcomes of surgery for aortic root aneurysms: a propensity-matched comparison of valve-sparing and composite valve graft replacement. J Thorac Cardiovasc Surg. 2015;150:1120-9.e1.

15. Burman ED, Keegan J, Kilner PJ. Aortic root measurement by cardiovascular magnetic resonance: specification of planes and lines of measurement and corresponding normal values. Circ Cardiovasc Imaging. 2008;1:104-13.

16. Dyverfeldt P, Bissell M, Barker AJ, Bolger AF, Carlhäll C-J, Ebbers T, et al. 4D Flow cardiovascular magnetic resonance consensus statement. J Cardiovasc Magn Reson. 2015; 17:72.

17. Piatti F, Sturla F, Bissell MM, Pirola S, Lombardi M, Nesteruk I, et al. 4D Flow analysis of bav-related fluid-dynamic alterations: evidences of wall shear stres alterations in absence of clinically-relevant aortic anatomical remodeling. Frontiers Physiol. 2017;8.

18. Piatti F, Pirola S, Bissell M, Nesteruk I, Sturla F, Della Corte A, et al. Towards the improved quantification of in vivo abnormal wall shear stresses in BAV-affected patients from 4D-flow imaging: benchmarking and application to real data J Biomech. 2017;50:93-101.

19. David TE, David CM, Feindel CM, Manlhiot C. Reimplantation of the aortic valve at 20 years. J Thorac Cardiovasc Surg. 2017;153:232-8.

20. De Paulis R, De Matteis GM, Nardi P, Scaffa R, Bassano C, Chiariello L. Analysi of valve motion after the reimplantation type of valve-sparing procedure (David I) with a new aortic root conduit. Ann Thorac Surg. 2002;74:53-7.

21. Bissell MM, Dall'Armellina E, Choudhury RP. Flow vortices in the aortic root: in vivo 4D-MRI confirms predictions of Leonardo da Vinci. Eur Heart J. 2014; 35:1344.

22. Katayama S, Umetani N, Sugiura S, Hisada T. The sinus of Valsalva relieves abnormal stress on aortic valve leaflets by facilitating smooth closure. J Thorac Cardiovasc Surg. 2008;136:1528-35. 1535 e1

23. Markl M, Draney MT, Miller DC, Levin JM, Williamson EE, Pelc NJ, et al. Time-resolved three-dimensional magnetic resonance velocity mapping of aortic flow in healthy volunteers and patients after valve-sparing aortic root replacement. J Thorac Cardiovasc Surg. 2005;130:456-63.

24. D'Ancona G, Ciofalo R, Biondo D, Follis M, Follis F. Midterm follow-up dynamic echocardiography evaluation after ascending aorta replacement and reimplantation of the aortic valve (David operation) in a matched control study. Eur J Cardiothorac Surg. 2012;41:785-8.

25. Mignosa C, Mariani C, Deste W, Felis S, Di Stefano S, Giuffrida A, et al Long-term hemodynamic performance of the aortic valve after David I: an echocardiographic study. Semin Thorac Cardiovasc Surg. 2015;27: 257-63.

26. David TE, Feindel CM, David CM, Manlhiot C. A quarter of a century of experience with aortic valve-sparing operations. J Thorac Cardiovasc Surg. 2014;148:872-9; discussion 879-80

27. Lantelme P, Dzudie A, Milon H, Bricca G, Legedz L, Chevalier JM, et al Effect of abdominal aortic grafts on aortic stiffness and central hemodynamics. J Hypertens. 2009:27:1268-76.

28. Li Y, Gu H, Fok H, Alastruey J, Chowienczyk P. Forward and backward pressure waveform morphology in hypertension. Hypertension. 2017;69:375-81.

29. Callaghan FM, Kozor R, Sherrah AG, Vallely M, Celermajer D, Figtree GA, et al. Use of multi-velocity encoding 4D flow MRI to improve quantification of flow patterns in the aorta. J Magn Reson Imaging. 2016;43:352-63.

30. Piola M, Vismara R, Tasca G, Lucherini F, Redaelli P, Soncini M, et al. Design of a simple coronary impedance simulator for the in vitro study of the complex coronary hemodynamics. Physiol Measure. 2016;37:2274-85.

31. Moore BL, Dasi LP. Coronary flow impacts aortic leaflet mechanics and aortic sinus hemodynamics. Ann Biomed Eng. 2015;43:2231-41.

32. Ha H, Lantz J, Haraldsson H, Casas B, Ziegler M, Karlsson M, et al. Assessmen of turbulent viscous stress using ICOSA 4D Flow MRI for prediction of hemodynamic blood damage. Sci Rep. 2016;6:39773.

Key Words: aorta, 4D MRI, valve-sparing surgery, flow 